\title{
PENGARUH WAKTU PENUNDAAN PENGOLAHAN BUAH SAWIT Elaeis guineensis TERHADAP MUTU CRUDE PALM OIL DENGAN ALAT PENGOLAHAN SAWIT TIPE BATCH
}

\author{
Ivoni Susanti ${ }^{*}$, Fitria Lestari ${ }^{2}$
}

1,2STKIP PGRI Lubuklinggau, Jl. Mayor Toha Kel Air Kuti Kota Lubuklinggau 31626, Indonesia

*Corresponding author, e-mail: ivonijoe@gmail.com

\begin{abstract}
ABST RACT
This study aims to Analyze the effect of time delay on processing of palm fruit from Elaeis guineensis Jacq to Crude Palm Oil (CPO) quality. Fresh fruit marks are chopped to separate with fruit marks in the form of brondolan, then separated between inside and outside fruit and then treated with processing delays 0 hours, 6 hours, 12 hours, 18 hours and 24 hours. Further processed by using Batch type palm oil processing tool. CPO is analyzed CPO quality which consist of free fatty acid test, water content test and dirt level test. From result of measurement and quality test show the effect of time delay of processing of palm fruit to increase free fatty acid especially at treatment delay for 24 hours on fruit palm inside. The result of comparison of CPO quality measurement (ALB level, moisture content and dirt level) is still far below SNI standard.
\end{abstract}

Keywords: Elaeis guineensis Jacq, Free Fatty Acids, Levels of Impurities Moisture Content

\section{PENDAHULUAN}

Perkebunan kelapa sawit di Indonesia mulai berkembang pesat sejak awal tahun 80-an dan saat ini kelapa sawit sudah menjadi komunitas perkebunan yang berperan sangat penting dalam penerimaan devisa negara, penyerapan tenaga kerja serta sangat membantu dalam pengembangan perekonomian rakyat dan daerah. Pada tahun 2002 di Indonesia mencapai 4,3 juta ha dengan produksi minyak sawit Crude Palm Oil (CPO) lebih dari 9 juta ton (Elisabeth dan Ginting, 2003).

Indonesia merupakan produsen kelapa sawit terbesar kedua di dunia setelah Malaysia. Sebanyak 85\% lebih pasar dunia kelapa sawit dikuasai oleh Indonesia dan Malaysia. Indonesia diperkirakan menjadi produsen minyak kelapa sawit terbesar pertama di dunia pada tahun 2010. Hal ini menjadi tantangan esensial bagi para peneliti dalam hal pengolahan atau produksi, peningkatan mutu minyak dan pemuliaan kelapa sawit (Pamin, 1998).

Mutu minyak kelapa sawit sangat dipengaruhi oleh tingkat kematangan buah pada saat dipanen dan penangganan pasca panen sampai di Pabrik. Panen harus menghasilkan Tandan Buah Segar (TBS) pada kematangan optimal, pemanenan pada tandah buah mentah (belum optimal) cenderung akan mengakibatkan berkurangnya jumlah minyak yang dihasilkan, dan sebaliknya pemanenan yang terlalu matang dan penanganan yang lambat (penyimpanan) atau busuk akan menghasilkan minyak dengan kandungan Free Fatty Acid (Asam Lemak Bebas/ALB) yang tinggi.

Penyimpanan menyebabkan kadar asam lemak bebas yang tinggi, oleh sebab itu penanganan pasca panen harus segera dilakukan mengingat tandan buah kelapa sawit akan mengalami penurunan mutu dalam kurun waktu 8 sampai 24 jam setelah panen (Hudori, 2016). Permasalahan ini sangat merugikan perusahaan perkebunan 
sawit maupun petani sawit. Alternatif yang dapat diberikan, dengan mengetahui tingkat kematangan dan rentan waktu penundaan dapat mempengaruhi mutu CPO. Untuk itu perlu dilakukan penelitian mengenai lamanya waktu penundaan pengolahan sawit menggunakan alat pengolah sawit yang dirancang secara sederhana dengan kapasitas $5 \mathrm{~kg}$ sampai $10 \mathrm{~kg}$ dengan tipe Batch.

Berdasarkan uraian di atas dipandang perlu diadakan penelitian "Pengaruh Waktu Penundaan Pengolahan Buah Sawit Elaeis guineensis Jacq Terhadap Mutu Crude Palm Oil (CPO) dengan Alat Pengolahan Sawit Tipe Batch".

\section{METODE}

Persiapan buah sawit dalam bentuk brondolan, dengan cara Tandan Buah Segar (TBS) sawit dipisahkan buahnya menjadi dua kelompok, yaitu buah bagian luar yang sudah masak dan buah yang bagian dalam yang kurang masak. Masing-masing kelompok tersebut dibuat perlakuan penundaan pengolahan buah sawit dengan modifikasi variasi dari Alfiah \& Susanto (2015) yaitu 0 jam, 6 jam, 12 jam, 18 jam dan 24 jam. Setiap perlakuan diolah dengan alat pengolah sawit tipe Batch (Gambar 1). Kemudian CPO yang dihasilkan dilakukan penguji mutu yang meliputi \% ALB, Kadar Air dan Kadar Kotoran). Modifikasi pengolah Sawit Tipe Batch dapat dilihat pada Gambar 1.

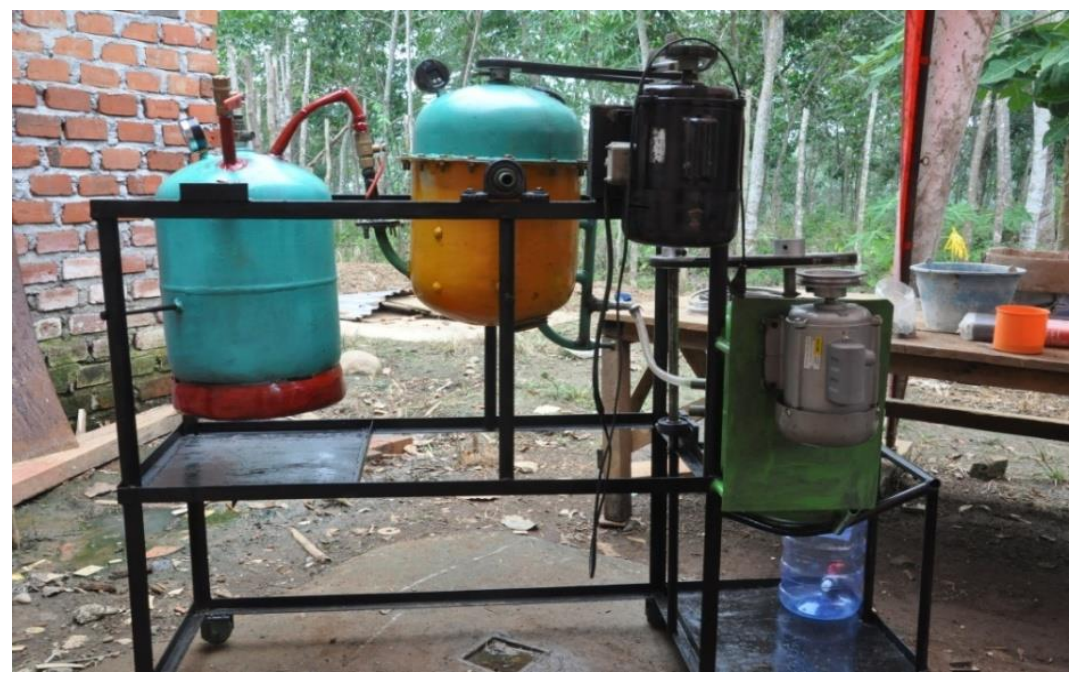

Gambar 1. Alat Pengolah Sawit Tipe Batch (Sumber: Dokumentasi Peneliti)

\section{Uji Asam Lemak Bebas (ALB)}

Pengukuran rendemen dan mutu CPO dengan cara:

Tahapan Uji Asam Lemak Bebas (ALB) (Iqbal et al., 2018) yaitu: a) CPO dipanaskan pada suhu $45-50^{\circ} \mathrm{C}$ dan diaduk hingga homogen, b) CPO ditimbang sebanyak 5 gram ke dalam gelas gelas beaker $100 \mathrm{ml}$ yang bersih dan kering yang telah diketahui berat kosongnya, c) Ditambahkan larutan alkohol 95\% sebanyak 75 $\mathrm{ml}$ dan inidikator fenolftalein 1\% sebanyak 3 tetes, d) Lalu dititrasi dengan larutan standar $\mathrm{KOH}$ 0,0999 $\mathrm{N}$ sampai terjadi perubahan warna dari kuning menjadi merah lembayung, e) Dicatat volume $\mathrm{KOH} \mathrm{0,0999} \mathrm{N} \mathrm{pada} \mathrm{titik} \mathrm{akhir} \mathrm{tetrasi} \mathrm{dan} \mathrm{f)} \mathrm{Dihitung}$ persentase ALB dengan menggunakan rumus:

$$
\% \text { ALB }=\frac{\text { VKOH X NKOH X M }}{W S X 1000} x 100
$$


Keterangan:

$\begin{array}{ll}\mathrm{V} \mathrm{KOH} & =\mathrm{ml} \mathrm{KOH} \\ \mathrm{N} \mathrm{KOH} & =\mathrm{N} \mathrm{KOH} \\ \mathrm{M} & =\mathrm{BM} \text { asam palmitat }=256 \\ \mathrm{WS} & =\text { berat sampel }(\mathrm{mg})\end{array}$

\section{Uji Kadar Air}

Tahapan Uji kadar air adalah sebagi berikut (Yulianto, 2019): a) Sampel yang sudah dipanaskan $45-50^{\circ} \mathrm{C}$ diaduk dahulu agar homogen, b) CPO ditimbang seberat 20 gram ke dalam cawan petri yang sudah diketahui berat kosongnya, c) CPO yang telah ditimbang kemudian dipanaskan selama 15-25 menit di atas hot plate hingga seluruh air menguap, kemudian didinginkan selama 15 menit dalam desikator, d) Ditimbang kembali Berat CPO yang sudah dipanaskan dan e) Dihitung kadar air CPO dengan menggunakan rumus:

Keterangan:

$$
\% \operatorname{AIR}=\frac{A-B}{C} x 100
$$

$\mathrm{A}=$ Berat $\mathrm{CPO}$ sebelum dipanaskan (gram)

$\mathrm{B}=$ Berat $\mathrm{CPO}$ sesudah dipanaskan (gram)

$\mathrm{C}=$ Berat sampel (gram)

\section{Uji Kadar Kotoran}

Tahapan Uji kadar kotoran adalah sebagai berikut (Irianto \& Apriyanto, 2012):

a) Sampel CPO yang sudah dipanaskan $45-50^{\circ} \mathrm{C}$ diaduk sampei homogen, b) Ditimbang sampel seberat 20 gram ke dalam gelas erlemenyer $250 \mathrm{ml}$ yang telah diketahui berat kosongnya, c) Ditambahkan $100 \mathrm{ml}$ larutan xeksan dan diaduk sampai CPO larut, d) disaring CPO dengan kertas saring yang telah diketahui berat kosong dan filtratnya bebas dari minyak, e) Kertas saring dikeringkan dalam oven pada suhu $\pm 105^{\circ} \mathrm{C}$ selama 60 menit, f) Lalu didinginkan dalam desikator \pm 15 menit dan ditimbang sampai diperoleh berat yang konstan dan g) Hitung kadar kotoran CPO dengan menggunakan rumus:

Keterangan:

$$
\text { \%kotoran }=\frac{A-B}{C} \times 100
$$

A = Berat kertas saring + kotoran (gram)

$\mathrm{B}=$ Berat kertas saring (gram)

$\mathrm{C}=$ Berat sampel (gram)

Mutu CPO pada setiap perlakuan akan dianalisis secara statistik yaitu dengan uji anava untuk mengetahui perbedaan setiap perlakuan. Selanjutnya, data-data setiap perlakuan penundaan pengolahan buah sawit dianalisa secara grafis dan dibandingkan standar mutu CPO berdasarkan SNI.

\section{HASIL DAN PEMBAHASAN}

\section{Hasil Analisis Mutu CPO (ALB, Kadar Air dan Kadar Kotoran)}

Dilihat mutu CPO hasil penelitian kadar air dan kadar kotoran masih jauh dibawah mutu CPO standar SNI. Berarti pengolahan sawit dengan menggunakan alat pengolah sawit tipe Batch masih memiliki kelemahan yang sangat berarti, dan perlu dilakukan penelitian lanjutan untuk pengembangan metode yang lebih baik untuk 
mendapatkan hasil yang lebih sempurna. Hasil Analisis Mutu CPO (ALB, Kadar Air dan Kadar Kotoran) pada penelitian ini dapat dilihat pada Tabel 1.

Tabel 1. Perbandingan Mutu CPO Hasil Penelitian dengan Mutu Standar SNI

\begin{tabular}{|c|c|c|c|c|}
\hline \multirow{2}{*}{ Kriteria } & \multirow{2}{*}{ Perlakuan } & \multicolumn{2}{|c|}{ Hasil Penelitian } & \multirow{2}{*}{ Data SNI ( \%) } \\
\hline & & Buah Dalam (\%) & Buah Luar (\%) & \\
\hline \multirow[t]{5}{*}{ ALB } & 0 Jam & 2,10 & 1,92 & 5,0 \\
\hline & 6 Jam & 2,33 & 2,30 & \\
\hline & $12 \mathrm{Jam}$ & 3,07 & 2,40 & \\
\hline & $18 \mathrm{Jam}$ & 3,24 & 3,20 & \\
\hline & $24 \mathrm{Jam}$ & 3,83 & 3,24 & \\
\hline \multirow[t]{5}{*}{ Kadar Air } & 0 Jam & 0,42 & 0,62 & 0,45 \\
\hline & 6 Jam & 0,56 & 0,97 & \\
\hline & 12 Jam & 1,14 & 0,39 & \\
\hline & $18 \mathrm{Jam}$ & 0,91 & 1,04 & \\
\hline & $24 \mathrm{Jam}$ & 0,54 & 0,63 & \\
\hline \multirow[t]{5}{*}{ Kadar Kotoran } & 0 Jam & 0,24 & 0,31 & 0,05 \\
\hline & 6 Jam & 0,13 & 0,31 & \\
\hline & 12 Jam & 0,29 & 0,27 & \\
\hline & $18 \mathrm{Jam}$ & 0,28 & 0,31 & \\
\hline & $24 \mathrm{Jam}$ & 0,41 & 0,18 & \\
\hline
\end{tabular}

Kualitas minyak kelapa sawit ditentukan oleh kadar Asam Lemak Bebas (ALB), kandungan air, dan mudah tidaknya minyak tersebut dijernikan. Minyak kelapa sawit yang baik adalah minyak yang memiliki kadar ALB, air dan bahan-bahan kotoran lainnya yang rendah. Minyak sawit mentah harus memenuhi standar mutu pabrik dengan persyaratan: ALB maksimal 3,5\%, kandungan air maksimal 0,15\%, kadar kotoran maksimal 0,015. Standar mutu pabrik harus lebih baik dari pada standar mutu internasional karena semakin baik mutu yang dihasilkan pabrik akan memberikan kemungkinan lebih baik pula sesampainya di tempat tujuan negara pengimpor. Adapun persyaratan perdagangan internasional adalah: ALB maksimal 5\%, kadar air 0,5\% dan kadar kotoran 0,05\% (Setyamidjaja, 2006).

\section{Mutu CPO}

a. Asam Lemak Bebas (ALB)

Hasil analisis Asam Lemak Bebas (ALB) pada CPO dapat dilihat pada Gambar 2.

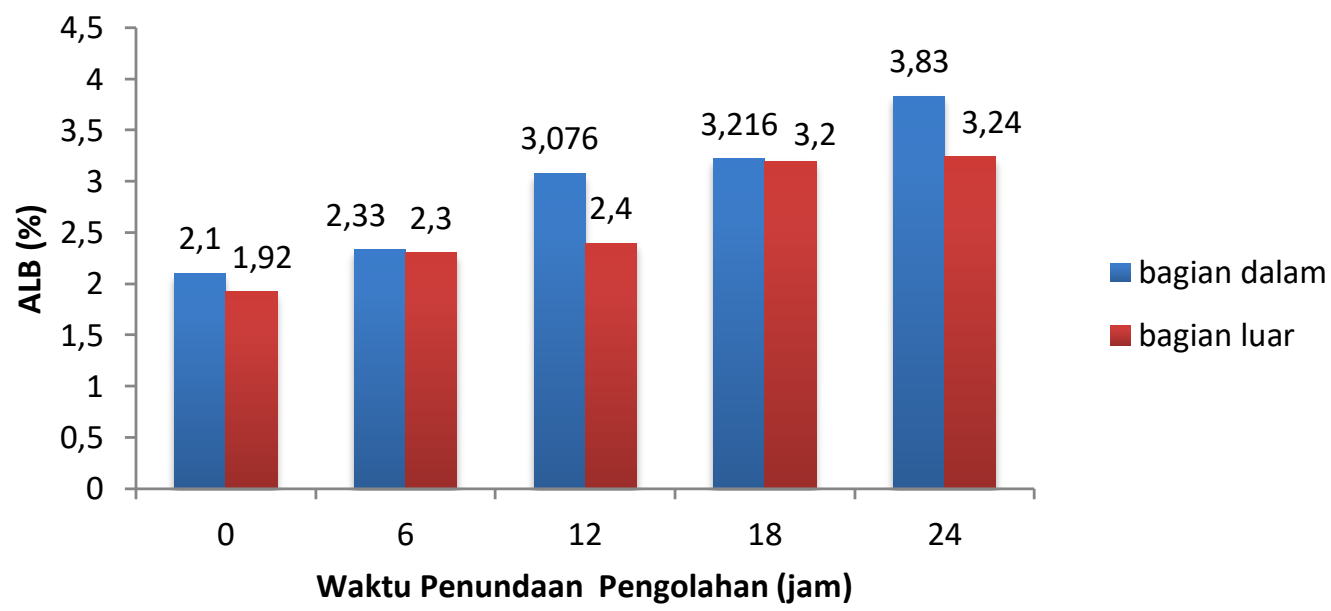

Gambar 2. Perbandingan Persentase ALB buah dalam dan Luar 
Berdasarkan Gambar 2 diketahui bahwa pada buah luar \% ALB lebih rendah dibandingkan buah bagian dalam. Sedangkan berdasarkan teori buah luar seharusnya memiliki \% ALB yang lebih tinggi, karena tingkat kematangan buah bagian luar lebih cepat (masak) dibandingkan dengan buah dalam (kurang masak). Hal ini disebabkan pada saat perontokan brondolan dari Tandan Buah Segar (TBS) dilakukan secara manual dengan pencacahan. Pada saat pencacahan dari TBS, buah bagian dalam memiliki tingkat kesukaran yang lebih tinggi pada proses pelepasan brondolan dari TBS sehingga buah banyak mengalami kerusakan dan pelukaan. Kerusakan dan pelukaan ini dapat menyebabkan asam lemak bebasnya meningkat, karena enzim lipase yang ada dalam buah masih aktif sehingga pada saat minyak keluar dari daging buah terjadi reaksi antara minyak dan enzim yang dapat menyebabkan ALB meningkat (Fauzi et al., 2012).

Pada perlakuan penundaan waktu pengolahan berdasarkan analisa statistik menunjukan adanya perbedaan yang nyata terhadap peningkatan ALB. Persentase ALB akan berubah dengan nyata, dengan adanya perubahan waktu, dimana \% ALB akan terus mengalami peningkatan secara dratis terutama pada perlakuan waktu penundaan 12 jam. Hasil ini dibenarkan oleh Fauzi et al. (2012) yang menyatakan bahwa, tandan buah segar yang baru dipanen harus segera diolah dan tidak boleh melebihi penundaan delapan jam setelah panen, karena buah yang tidak segera diolah akan mengalami kerusakan yang dapat menyebabkan asam lemak bebas meningkat.

Penundaan pengolahan dapat meningkatkan asam lemak bebas, hal ini disebabkan buah yang ditunda pengolahannya sudah merupakan brondolan (lepas dari tandan buah), dimana sudah ada bagian yang terluka (pelukaan) sehingga enzim lipase yang masih aktif yang terselubung pada lapisan vakuola akan bereaksi dengan minyak menghasilkan gliserol dan asam lemak bebas. Reaksi ini dapat terjadi secara oksidasi dan hidrolisis (Ihsan \& Fajri, 2019). Enzim lipase ini mengkatalis reaksi pada daerah interface antara air dan minyak, kemampuan enzim pada daerah interface ini sangat mempengaruhi kecepatan reaksi, dimana semakin luas daerah interface kecepatan reaksi akan semakin besar. Penundaan semakin lama dan pelukaan semakin besar dapat menyebabkan kerja enzim akan semakin cepat, maka dari itu Hasibuan \& Ijah (2017) mengatakan bahwa enzim lipase dapat menyebabkan kerusakan mutu minyak.

Penundaan pengolahan buah sawit sangat mempengaruhi persentase ALB yang pada CPO yang dihasilkan, ini dapat terlihat pada Gambar 2. Pada grafik tersebut menunjukan bahwa semakin lama penundaan pengolahan buah sawit, maka ALB yang dihasilkan akan semakin tinggi. Peningkatan ALB berkisar antara 1,92\% sampai dengan 3,83\%, dimana peningkatan yang terjadi masih memenuhi standar mutu SNI dengan persyaratan: ALB maksimal 5,0\% (SNI, 1992).

Asam Lemak Bebas (ALB), yaitu asam yang dibebaskan pada hidrolisis lemak. ALB tinggi menunjukkan suatu ukuran tentang ketidakberesan dalam panen dan pengolahan (Mangoensoekarjo \& Semangun, 2003). Kadar asam lemak bebas yang tinggi akan menyebabkan turunnya mutu CPO yang dihasilkan yang akan menyebabkan ketengikan pada minyak, membuat rasanya tidak enak, terjadinya perubahan warna dan juga rendemen minyak menjadi turun. Maka untuk menekan kadar asam lemak bebas ini, perlu dilakukan tindakan pencegahan sedini mungkin dengan menerapkan tindakan koordinasi Panen, Angkut dan Olah (PAO). Tindakan pengolahan yang segera harus dilakukan untuk menekan terbentuknya asam lemak 
bebas kelapa sawit dengan cara dilakukan pemanasan dengan suhu antara $90^{\circ} \mathrm{C}$ $100^{\circ} \mathrm{C}$ menggunakan panas uap air (Setyamidjaja, 2006).

Pemanenan dan pengolahan buah sawit harus dilakukan pada saat yang tepat, karena pemanenan dan pengolahan yang tepat akan menentukan tercapainya kualitas dan kuantitas minyak sawit yang dihasilkan. Saat panen dan pengolahan yang tepat berhubungan dengan proses pembentukan minyak di dalam buah. Buah yang lewat masak, sebagian kandungan minyaknya akan berubah menjadi asam lemak bebas (free fatty acid) yang akan menurunkan mutu minyak kelapa sawit (Setyamidjaja, 2006).

b. Kadar Air

Hasil analisis kadar air CPO dapat dilihat pada Gambar 3.

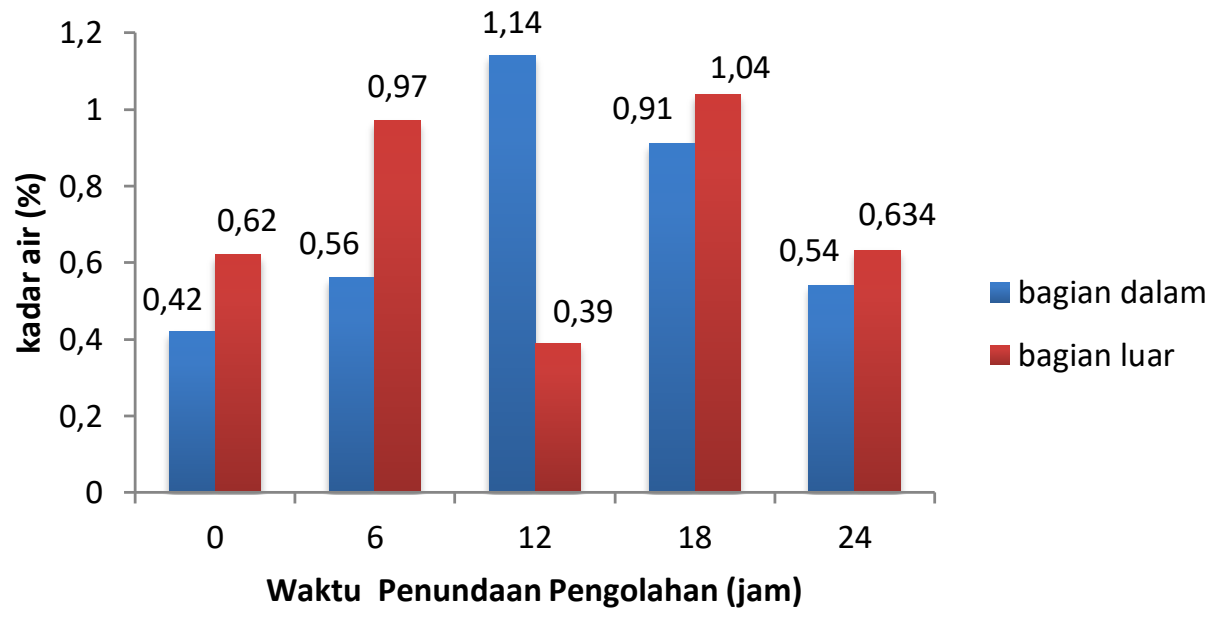

Gambar 3. Grafik Perbandingan Kadar Air Buah Dalam dan Luar

Berdasarkan analisis statistik pada persentase kadar air terhadap perlakuan pemisahan buah dalam dan buah luar serta perlakuan waktu penundaan pengolahan, tidak menunjukan adanya perbedaan yang nyata pada uji lanjut anava. Dalam penelitian Ini menandakan bahwa, waktu penundaan pengolahan tidak menunjukan adanya keterkaitan dengan persentase kadar air yang ada dalam CPO. Pada gambar 3 dapat dilihat bahwa kadar air pada berbagai perlakuan berkisar antara 0,39\% sampai 1,14 \%. Persentase kadar air disetiap perlakuan pada penelitian ini diatas standar mutu yang telah ditetapkan SNI (1992), yaitu maksimal 0,45 \%. Hasil ini menunjukan bahwa mutu CPO yang dihasilkan dengan menggunakan alat pengolah sawit tipe Batch masih rendah jika dibandingkan dengan CPO berdasarkan ajuan standar pengolahan pabrik.

Perbedaan persentase kadar air yang tinggi pada CPO yang dihasilkan pada penelitian ini, sangat erat kaitannya dengan teknik pengolahan terutama pada proses pemurnian CPO. Pengolahan dan pemurnian CPO dengan menggunakan alat pengolah sawit tipe Batch sangat sederhana terutama pada saat pemisahan antara CPO dengan air. Pemisahan dilakukan dengan teknik pemanasan secara manual menggunakan kompor gas dan mesin pengaduk sehingga pemisahan antara CPO dengan air tidak berlangsung dengan sempurna. Sedangkan proses pemurnian CPO yang dilakukan di pabrik menggunakan peralatan atau mesin yang canggih (modern). Menurut Pahan (2007) ada tiga metode yang dilakukan dalam pemurnian minyak kasar, yaitu metode pengendapan (settling), metode pemusingan (centrifuge), dan metode pemisahan 
biologis. Metode-metode ini bertujuan untuk pemurnian minyak kasar dari kotoran, baik berupa padatan (solid), lumpur (sludge), maupun air agar diperoleh minyak dengan kualitas sebaik mungkin.

Peningkatan kadar air yang cukup tinggi sangat memungkinkan akan terjadi hidrolisa pada trigliserida atau minyak menjadi gliserol dan asam lemak bebas, karena menurut Muchtadi (2009) reaksi hidrolisa yang terjadi pada minyak akan mengakibatkan kerusakan minyak karena terdapat sejumlah air dalam minyak tersebut dan menyebabkan terbentuknya asam lemak bebas dan beberapa gliserol. Menurut Mualifah (2009), kadar air terbentuk dalam minyak merupakan salah satu parameter untuk menentukan tingkat kemurnian minyak dan berhubungan dengan kekuatan daya simpannya, sifat goreng, bau dan rasa. Kadar air sangat menentukan kualitas dari minyak yang dihasilkan. Kadar air berperan dalam proses oksidasi maupun hidrolisis minyak yang akhirnya dapat menyebabkan ketengikan. Semakin tinggi kadar air, minyak akan semakin cepat tengik. Hal tersebut juga dibenarkan pula oleh Buckle et al. (2010), bahwa hidrolisa minyak dan lemak menghasilkan asam-asam lemak bebas yang dapat mempengaruhi cita-rasa dan bau pada bahan itu. Hidrolisa dapat disebabkan oleh adanya air dalam lemak atau minyak atau karena kegiatan enzim (Mamuaja, 2017).

c. Kadar Kotoran

Hasil analisis kadar kotoroan CPO dapat dilihat pada Gambar 4.

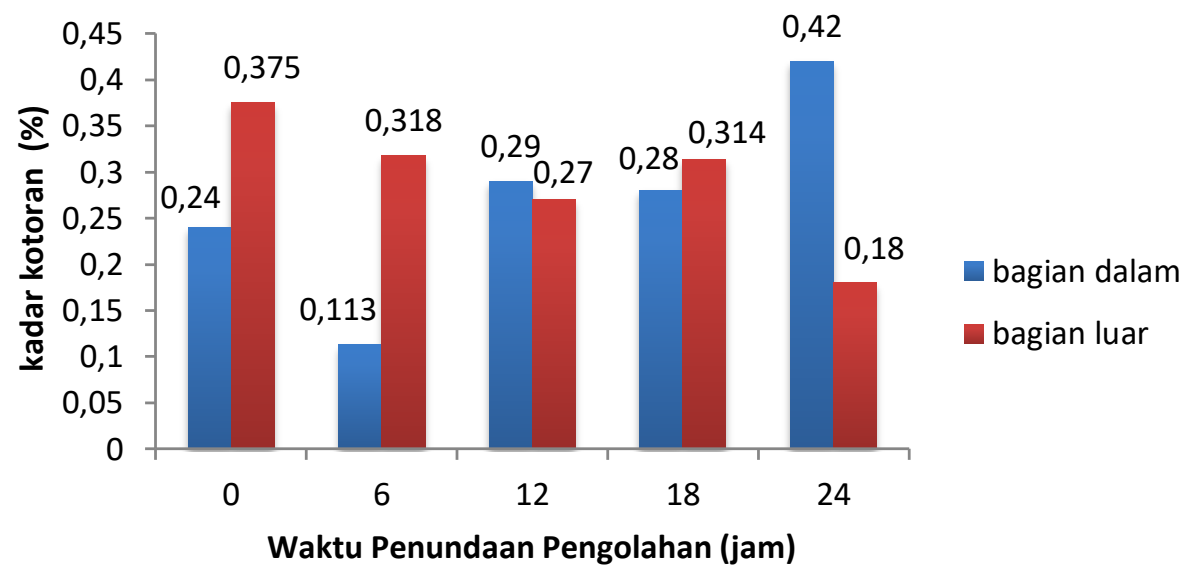

Gambar 4. Perbandingan kadar Kotoran Buah dalam dan Luar

Berdasarkan analisis statistik kadar kotoran terhadap perlakuan pemisahan buah dalam dan buah luar serta perlakuan waktu penundaan pengolahan, tidak menunjukan adanya perbedaan yang nyata pada uji lanjut anava. Hasil penelitian ini menunjukan bahwa tidak adanya pengaruh perlakuan pemisahan buah dan penundaan waktu pengolahan terhadap persentase kadar kotoran.

Pada Gambar 4, kadar kotoran CPO pada berbagai perlakuan berkisar 0,11\% sampai 0,42 \%. Hal ini menunjukan bahwa, kadar kotoran CPO yang dihasilkan pada setiap perlakuan persentasenya jauh lebih tinggi dibandingkan dengan standar mutu yang telah ditetapkan SNI (1992) yaitu 0,05\%. Hasil ini dapat dikatakan tidak memenuhi standar mutu atau kualitas CPO yang dihasilkan masih tergolong rendah. Perbedaan yang signifikan antara persentase kotoran CPO berdasarkasn standar mutu SNI dengan persentase kotoran CPO yang dihasilkan dengan menggunakan alat pengolah sawit tipe batch sangat dipengaruh oleh proses pengolahan terutama pada tahap pemurnian dan penjernian 
Pada penelitian ini, tahap pemisahan antara CPO dengan kotoran dilakukan dengan cara pengempaan dan penyaringan dengan menggunakan peralatan yang sangat sederhana yang dilakukan secara manual, sehingga hanya kotoran yang berupa serabut kasar dan karnel saja yang tersaring, sedangkan kotoran dalam bentuk partikel-partikel yang lebih kecil tidak tersaring. Dengan demikian persentase kotoran pada CPO yang dihasilkan masih sangat tinggi (Hudori, 2011). Salah satu faktor yang mempengaruhi mutu CPO adalah Kadar kotoran, karena kadar kotoran yang tinggi pada CPO dapat menyebabkan CPO tidak mudah dilakukan penjernihan yang dapat berakibat rendahnya mutu CPO (Maulana \& Susanto, 2015).

\section{SIMPULAN}

Hasil penelitian pengaruh waktu penundaan pengolahan buah sawit Elaeis guineensis terhadap mutu Crude Palm Oil (CPO) dengan alat pengolahan sawit tipe batch diperoleh mutu CPO masih dibawah standar SNI.

\section{REFERENSI}

Alfiah, C \& Susanto, H.W. (2015). Penanganan pasca Panen Kelapa Sawit (Penyemprotan $\mathrm{CaCl}_{2}$ Dan Kalium Sorbat Terhadap Mutu Crude Palm Oil). Jurnal Pangan dan Agroindustri, 3(1), 61-72.

Buckle, K. A., Edwards, R. A., Fleet, G. H. \& Wootton, M. (2010). Ilmu Pangan. Jakarta: Universitas Indonesia (UI-Press).

Elisabeth, J., \& Ginting S.P. (2003). Pemanfaatan Hasil Samping Industri Kelapa Sawit Sebagai Bahan Pakan Ternak Sapi Potong. Prosiding Lokakarya Nasional: Sistem Integrasi Kelapa Sawit-Sapi. Bengkulu 9 - 10 September 2003.

Fauzi, Y., Widyastuti,Y., Satyawibawa,I., \& Paeru, R. (2012). Kelapa Sawit. Jakarta: Penebar Swadaya.

Hasibuan, A.H \& Ijah. (2017). Enzimatik Esterifikasi Menggunakan Lipase Antara Asam Lemak Sawit Destilat dan Gliserol Untuk Sintesis Triasilgliserol. Warta IHP/Journal of Agro-based Industry, 34(2), 58-64.

Hudori, M. (2011). Analisa Faktor Penyebab Tingginya Kadar Kotoran pada Produksi Minyak Kelapa Sawit. Jurnal Citra Widya Edukasi, 3(1), 21-27.

Hudori, M. (2016). Operation Management Perencanaan Kebutuhan Kendaraan Angkutan Tandan Buah Segar (TBS) di Perkebunan Kelapa Sawit. Industrial Engineering Journal 5(1), 23-28.

Ihsan, N.F., \& Fajri, R. (2019). Pengaruh Kadar Free Fatty Acid (FFA) dalam Bulk Stronge Tank (BST) terhadap Kualitas Crude Palm Oil (CPO) Hasil Produksi Pengolahan Kelapa Sawit PMKS PT. Sisirau Aceh Tamiang. Quimica: Jurnal Kimia Sains dan Terapan, 1(1), 22-24.

Iqbal, Z., Herodian, S \& Widodo, S. (2018). Evaluasi Non-Destrustif Kandungan Asam Lemak Bebas (Alb) Tandan Buah Segar (Tbs) Kelapa Sawit Dengan Metode Nir Spektroskopi Non-Destructive. Jurnal Teknik Pertanian Lampung, 7(2), 80-87.

Irianto \& Apriyanto, M. (2012). Analisa Mutu Minyak Kelapa Sawit Mentah Di Pom Iv Nyato Pt. Th Indo Plantations Kecamatan Pelangiran Kabupaten Indragiri Hilir Riau. Jurnal Teknologi Pertanian, 1(2), 47-56.

Mamuaja, F.C. (2017). Lipida. Manado: Unsrat Press.

Mangoensoekarjo, S \& Semangun. (2003). Manajemen Agrobisnis Kelapa Sawit. Yogyakarta: Gajah Mada University Press. 
Maulana, F.A \& Susanto, H.W. (2015). Pengaruh Penyemprotan Larutan Kalsium Propionat Dan Kalium Sorbat Pada Pasca Panen Kelapa Sawit (Elais guineensis Jacq) Terhadap Kualitas CPO. Jurnal Pangan dan Agroindustri, 3(2), 453-463.

Mualifah, S. (2009). Penentuan Angka Asam Thiobarbiturat Dan Angka Peroksida Pada Minyak Goreng Bekas Hasil Pemurnian Dengan Karbon Aktif Dari Biji Kelor (Moringa oleifera, Lamk). Skripsi, Universitas Islam Negeri Maulana Malik Ibrahim.

Muchtadi, D. ( 2009). Pengantar Ilmu Gizi. Bandung: CV. Alfabeta.

Pahan, I. (2007). Panduan Lengkap Kelapa Sawit Manajemen Agribisnis Dari Hulu Hingga Hilir. Jakarta: Penebar Swadaya.

Pamin, K. (1998). Seratus Tahun dan Lima Puluh Tahun Pengembangan Kelapa Sawit Indonesia : Dari Kebun Raya Bogor Menuju Industri. Konferensi Internasional Kelapa Sawit 23-25 September 1998.

Sari, D. M. (2003). Studi Keamanan Dan Cemaran Logam Berat (Pb dan Cu) Makanan Jajanan Di Bursa Kue Subuh Pasar Senen. Jakarta Pusat. Skripsi. Institut Pertanian Bogor.

Setyamidjaja, D. (2006). Kelapa Sawit, Teknik Budidaya, Panen dan Pengolahan. Yogyakarta: Penerbit Kanisius.

Yulianto. (2019). Analisis Quality Control Mutu Minyak Kelapa Sawit Di Pt. Perkebunan Lembah Bhakti Aceh Singkil AMINA: Ar-Raniry Chemistry Journal $1(2), 72-78$. 